Fixed Point Theory, 21(2020), No. 1, 221-238

DOI: $10.24193 /$ fpt-ro.2020.1.16

http://www.math.ubbcluj.ro/ nodeacj/sfptcj.html

\title{
ORBITAL FIXED POINT CONDITIONS IN GEODESIC SPACES
}

\author{
W.A. KIRK* AND NASEER SHAHZAD** \\ * Department of Mathematics, University of Iowa \\ Iowa City, IA 52242-1419, USA \\ E-mail: william-kirk@uiowa.edu \\ ** Department of Mathematics, King Abdulaziz University \\ P.O.B. 80203, Jeddah 21589, Saudi Arabia \\ E-mail: nshahzad@kau.edu.sa
}

\begin{abstract}
Many metric fixed point results can be formulated in an abstract 'convexity structure' setting. This discussion contains a review of some of these, as well as a discussion of other results which seem to require a bit more structure on the space. A metric space $(X, d)$ is said to be $\Gamma$ uniquely geodesic if $\Gamma$ is a family of geodesic segments in $X$ and for each $x, y \in X$ there is a unique geodesic $[x, y] \in \Gamma$ with endpoints $x$ and $y$. Let $X$ be $\Gamma$-uniquely geodesic and let $\mathfrak{C}(X)$ denote the family of all bounded closed convex (relative to $\Gamma$ ) subsets of $X$. Assume that the family $\mathfrak{C}(X)$ is compact in the sense that every descending chain of nonempty subsets of $\mathfrak{C}(X)$ has a nonempty intersection. This is a brief discussion of what additional conditions on a mapping $T: K \rightarrow K$ for $K \in \mathfrak{C}(X)$ always assure that has at least one fixed point. In particular it is shown that if the balls in $X$ are $\Gamma$-convex and if the closure of a $\Gamma$-convex set in $X$ is again $\Gamma$-convex then a mapping $T: K \rightarrow K$ always has a fixed point if it is nonexpansive with respect to orbits in the sense of Amini-Harandi, et al., and if for each $x \in K$ with $x \neq T(x)$,
\end{abstract}

$$
\inf _{m \in \mathbb{N}}\left\{\limsup _{n \rightarrow \infty} d\left(T^{m}(x), T^{n}(x)\right)\right\}<\operatorname{diam}(O(x)) .
$$

Mappings of the above type include those which are pointwise contractions in the sense that for each $x \in K$ there exists $\alpha(x) \in(0,1)$ such that

$$
d(T(x), T(y)) \leq \alpha(x) d(x, y) \text { for all } y \in K .
$$

The results discussed here extend known results if $K$ is a weakly compact (convex) subset of a Banach space. A number of open questions are raised in connection with characterizations of normal structure in certain geodesic spaces.

Key Words and Phrases: Normal structure, compact convexity structures, nonexpansive mappings, fixed points, dimihishing orbital diameters, pointwise contractions, mappings nonexpansive with respect to orbits, strictly contractive mappings, geodesic spaces.

2010 Mathematics Subject Classification: 54H25, 47H10, 47H09.

Acknowledgement. The authors would like to thank the anonymous reviewer for invaluable comments and suggestions. This article was funded by the Deanship of Scientific Research (DSR), King Abdulaziz University (KAU), Jeddah. Therefore, the authors acknowledge with thanks DSR, KAU for financial support. 


\section{REFERENCES}

[1] M.A. Alghamdi, W.A. Kirk, N. Shahzad, Remarks on convex combinations in geodesic spaces, J. Nonlinear Convex Anal., 15(2014), no. 1, 49-59.

[2] A. Amini-Harandi, M. Fakhar, H.R. Hajishari, Weak fixed point property for nonexpansive mappings with respect to orbits in Banach spaces, J. Fixed Point Theory Appl., 18(2016), no. 3, 601-607.

[3] D. Ariza, C. Li, G. López-Acedo, The Schauder fixed point theorem in geodesic spaces, J. Math. Anal. Appl., 417(2014), no. 1, 345-360.

[4] L.P. Belluce, W.A. Kirk, Fixed-point theorems for certain classes of nonexpansive mappings, Proc. Amer. Math. Soc., 20(1969), 141-146.

[5] J. Bogin, A generalization of a fixed point theorem of Goebel, Kirk and Shimi, Canad. Math. Bull., 19(1976), no. 1, 7-12.

[6] M. Bridson, A. Haefliger, Metric Spaces of Non-positive Curvature, Grundlehren der Mathematischen Wissenschaften [Fundamental Principles of Mathematical Sciences], 319, SpringerVerlag, Berlin, 1999.

[7] M.S. Brodskiǔ, D.P. Milman, On the center of a convex set, (Russian), Doklady Akad. Nauk SSSR (N.S.), 59(1948), 837-840.

[8] F. Browder, Nonexpansive nonlinear operators in a Banach space, Proc. Nat. Acad. Sci. U.S.A., 54(1965), 1041-1044.

[9] T. Büber, W.A. Kirk, A constructive proof of a fixed point theorem of Soardi, Math. Japon., 41(1995), no. 2, 233-237.

[10] A.A. Gillespie, B.B. Williams, Fixed point theorem for nonexpansive mappings on Banach spaces with uniformly normal structure, Applicable Anal., 9(1979), no. 2, 121-124.

[11] D. Göhde, Zum Prinzip der kontraktiven Abbildung, (German), Math. Nachr., 30(1965), 251258.

[12] N. Hussain, M. A. Khamsi, On asymptotic pointwise contractions in metric spaces, Nonlinear Anal., 71(2009), no. 10, 4423-4429.

[13] M.A. Khamsi, W.A. Kirk, An Introduction to Metric Spaces and Fixed Point Theory, Pure and Applied Mathematics (New York), Wiley-Interscience, New York, 2001.

[14] W.A. Kirk, A fixed point theorem for mappings which do not increase distances, Amer. Math. Monthly, 72(1965), 1004-1006.

[15] W.A. Kirk, Nonexpansive mappings and the weak closure of sequences of iterates, Duke Math. J., 36(1969), 639-645.

[16] W.A. Kirk, On nonlinear mappings of strongly semicontractive type, J. Math. Anal. Appl., 27(1969), 409-412.

[17] W.A. Kirk, Fixed point theorems for nonexpansive mappings, 1970, Nonlinear Functional Analysis (Proc. Sympos. Pure Math., Vol. XVIII, Part 1, Chicago, Ill., 1968), 162-168, Amer. Math. Soc., Providence, R.I.

[18] W.A. Kirk, An abstract fixed point theorem for nonexpansive mappings, Proc. Amer. Math. Soc., 82(1981), no. 4, 640-642.

[19] W.A. Kirk, Nonexpansive mappings and normal structure in Banach spaces, Proceedings of Research Workshop on Banach Space Theory (Iowa City, Iowa, 1981), 113-127, Univ. Iowa, Iowa City, IA, 1982.

[20] W.A. Kirk, N. Shahzad, Normal structure and orbital fixed point conditions, J. Math. Anal. Appl., 463(2018), no. 2, 461-476.

[21] W.A. Kirk, X.K. Xu, Asymptotic pointwise contractions, Nonlinear Anal., 69(2008), no. 12, 4706-4712.

[22] T.C. Lim, Characterizations of normal structure, Proc. Amer. Math. Soc., 43(1974), 313-319.

[23] E. Llorens-Fuster, Orbitally nonexpansive mappings, Bull. Aust. Math. Soc., 93(2016), no. 3, 497-503.

[24] A. Nicolae, Generalized asymptotic pointwise contractions and nonexpansive mappings involving orbits, Fixed Point Theory Appl., 2010(2010), Art. ID 458265, 19 pp. 
[25] G. Oldani, D. Roux, Convexity structures and Kannan maps, Nonlinear Functional Analysis and its Applications (Maratea, 1985), 327-333, NATO Adv. Sci. Inst. Ser. C Math. Phys. Sci., 173, Reidel, Dordrecht, 1986.

[26] A. Papadopoulos, Metric Spaces, Convexity and Nonpositive Curvature, IRMA Lectures in Mathematics and Theoretical Physics, 6, European Mathematical Society (EMS), Zürich, 2005.

[27] J.-P. Penot, Fixed point theorems without convexity, Analyse Non Convexe (Proc. Colloq., Pau, 1977). Bull. Soc. Math. France Mém. No. 60(1979), 129-152.

[28] S. Prus, Geometrical Background of Metric Fixed Point Theory, Handbook of Metric Fixed Point Theory, 93-132, Kluwer Acad. Publ., Dordrecht, 2001.

[29] S. Reich, I. Shafrir, Nonexpansive iterations in hyperbolic spaces, Nonlinear Anal., 15(1990), no. $6,537-558$.

[30] P.M. Soardi, Existence of fixed points of nonexpansive mappings in certain Banach lattices, Proc. Amer. Math. Soc., 73(1979), no. 1, 25-29.

[31] C.S. Wong, Close-to-normal structure and its applications, J. Funct. Anal., 16(1974), 353-358.

[32] C.S. Wong, On Kannan maps, Proc. Amer. Math. Soc., 47(1975), 105-111.

Received: January 20, 2018; Accepted: January 10, 2019. 